\section{A newly developed bipolar-current needle-knife for endoscopic submucosal dissection of large colorectal tumors}

Recently, endoscopic submucosal dissection has been recommended for the treatment of large colorectal tumors. However, the use of this procedure for this indication is not widely accepted because of its technical difficulty and because of the risk of complications $[1,2]$. In order to minimize damage to deeper tissues, we have developed a novel endoscopic electrosurgical knife, the "B-Knife" (BSBK21S35/45; Zeon Medical Inc., Tokyo, Japan), that uses a bipolar current system.

The B-Knife has a diffusion electrode attached to the tip of its sheath and an active electrode attached to the knife on the end of the sheath. Needle length can be adjusted from $0 \mathrm{~mm}$ to $3.0 \mathrm{~mm}$. The knife also has a special resinoid coating which enables the current of electricity per unit area so-called "electric current density". Because the knife has been designed so that high-frequency electricity flows from the knife to the sheath tip, the amount of high-frequency current sent from the knife tip to the muscle layer has been reduced (Figure 1). In our experiments using resected colonic material from swine, no vertical electrothermal degeneration was detected in the muscularis propria after use of the B-Knife (ICC200, ERBE, set to 120 watts, effect 2, Endo-Cut mode off, and turned on for 15,30 , or 45 seconds).

Endoscopic submucosal dissection was carried out in three patients using the BKnife after informed consent was obtained. In all cases, $10 \%$ glycerin was injected into the submucosal layer. The electronic instrument was set at 30 watts, forced coagulation mode $[3,4]$. En bloc resection was achieved in all three cases (Figure $\mathbf{2}$, Video 1). None of the patients developed delayed bleeding or perforation. No recurrence was found on follow-up colonoscopy at 3 months.

These preliminary results suggest that endoscopic submucosal dissection using the B-Knife is a reliable and safe method for the complete resection of selected large flat lesions in the colorectum.

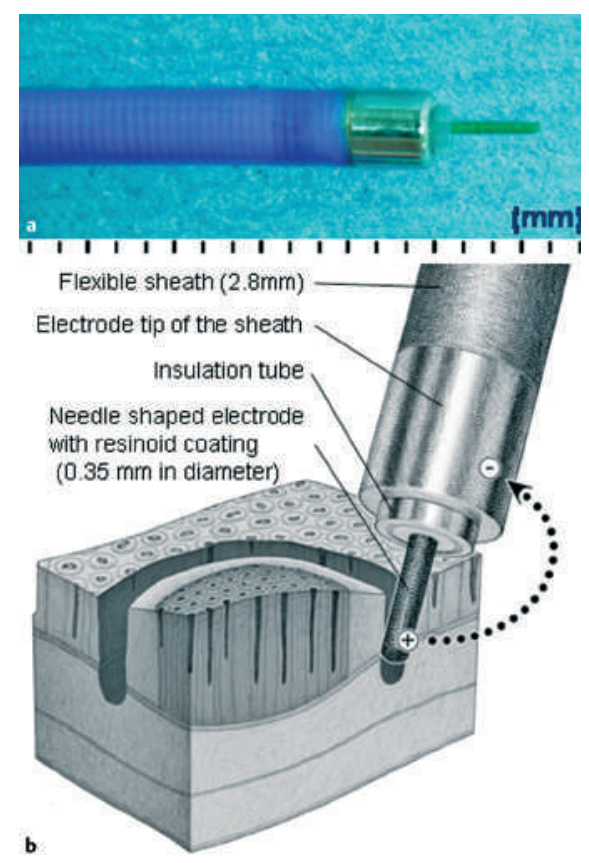

Figure 1 The B-Knife. a Photographic image showing the knife beside a millimeter scale. $\mathbf{b}$ Schematic view, showing the flow route of high-frequency electric current from the knife to the sheath tip.

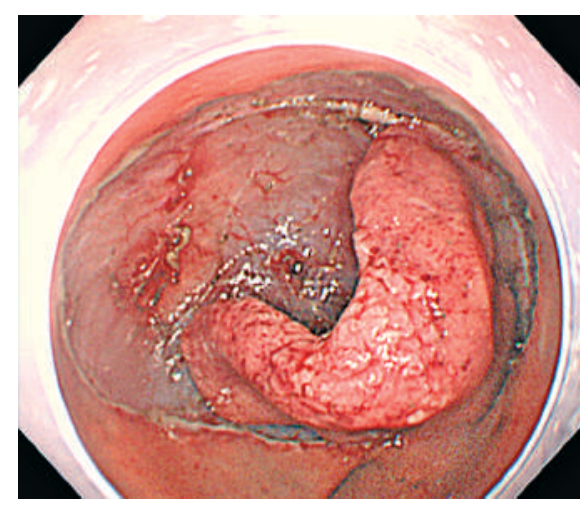

Figure 2 A large sessile lesion, $65 \mathrm{~mm}$ in diameter, in the upper rectum. En bloc resection was achieved by endoscopic submucosal dissection, which was performed using the BKnife (Video 1). The operating time was 50 minutes and there were no complications. Histopathologic evaluation revealed the lesion to be well-differentiated adenocarcinoma (depth of submucosal invasion $1000 \mu \mathrm{m}$ ); the margins were free of neoplasia.

Endoscopy_UCTN_Code_TTT_1AQ_2AD

\section{Video}

online content including video sequences viewable at:

www.thieme-connect.de/ejournals/abstract/ endoscopy/doi/10.1055/s-2006-944622

Y. Sano', K. I. Fu', Y. Saito², T. Doi', M. Hanafusa1, S. Fujii' ${ }^{3}$, T. Fujimori ${ }^{3}$, A. Ohtsu' ${ }^{1}$

${ }^{1}$ Division of Digestive Endoscopy and Gastrointestinal Oncology, National Cancer Center Hospital East, Chiba, Japan

2 Division of Endoscopy, National Cancer Center Hospital, Tokyo, Japan

${ }^{3}$ Department of Surgical and Molecular Pathology, Dokkyo University School of Medicine, Tochigi, Japan.

\section{References}

${ }^{1}$ Yamamoto H, Yahagi N, Oyama T. Mucosectomy in the colon with endoscopic submucosal dissection. Endoscopy 2005; 37: $764-$ 768

${ }^{2}$ Sano Y, Machida H, Fu KI et al. Endoscopic mucosal resection and submucosal dissection method for large colorectal tumors. Dig Endosc 2004; 16: S93-S96

${ }^{3}$ Greenwood J Jr. Two point coagulation: a follow-up report on a new technic and instrument for electrocoagulation in neurosurgery. Arch Phys Ther 1942; 23: 552-554

${ }^{4}$ Hellwig D, Haag R, Bartel V et al. Application of new electrosurgical devices and probes in endoscopic neurosurgery. Neurol Res 1999; 21: $67-72$

\section{Corresponding Author}

\section{Y. Sano, M.D.}

National Cancer Center Hospital

East (NCCHE)

Division of Digestive Endoscopy and Gastrointestinal Oncology

Kashiwanoha 6-5-1

Kashiwa

Chiba 277-8577

Japan

Fax: $\quad+81-4-7131-4724$

E-mail: ys_endoscopy@hotmail.com 